\title{
Traditional Kyrgyz Carpet Weaving Process and Semantics of Related Customs
}

\section{Chynykhan Satybaldieva', Mukaram Tashalieva ${ }^{2}$, Zamira Eshnazarova ${ }^{3}$, Ainura Tagaibekova1, Aizirek Satybaldieva ${ }^{4}$, Zhanara Tashalieva ${ }^{5}$, Zhypargul Abdullaeva ${ }^{*}$ (1)}

\author{
${ }^{1}$ Department of History, Archeology and Ethnography, Osh State University, Osh, Kyrgyzstan \\ ${ }^{2}$ Departmemnt of History, Kyrgyz-Uzbek University, Osh, Kyrgyzstan \\ ${ }^{3}$ South Department of Academy of Sciences, Osh, Kyrgyzstan \\ ${ }^{4}$ Department of Public Health and Well-Being, Osh State University, Osh, Kyrgyzstan \\ ${ }^{5}$ Department of Accounting and Customs, Financial-Juridical College, Osh State University, Osh, Kyrgyzstan \\ ${ }^{6}$ Science and Research Department, Osh State University, Osh, Kyrgyzstan \\ Email: *jypar.science@oshsu.kg
}

How to cite this paper: Satybaldieva, C., Tashalieva, M., Eshnazarova, Z., Tagaibekova, A., Satybaldieva, A., Tashalieva, Z., \& Abdullaeva, Z. (2021). Traditional Kyrgyz Carpet Weaving Process and Semantics of Related Customs. Advances in Anthropology, 11, 68-75.

https://doi.org/10.4236/aa.2021.111006

Received: February 2, 2021

Accepted: February 22, 2021

Published: February 25, 2021

Copyright $\odot 2021$ by author(s) and Scientific Research Publishing Inc. This work is licensed under the Creative Commons Attribution International License (CC BY 4.0).

http://creativecommons.org/licenses/by/4.0/

\begin{abstract}
Research relevance in this article is providing information about the traditional Kyrgyz carpet weaving process and semantics of related customs. Carpet weaving is the most popular form of Kyrgyz traditional handicraft. This craft is mainly seen as a women's activity. The process of carpet weaving is a combination of involved activities. The history of people's ethnic culture is deeply connecting with the way of life and the type of economy of certain people. Handicrafts are satisfying aesthetic needs and have a great practical value, as well as reflecting ethnic relations between people. One of the main material value categories in the Kyrgyz people custom is woven carpets and rugs. Recently, carpets and rugs have not lost their practical significance, and in some traditions of Kyrgyz life, carpets and rugs are the main attributes. Therefore, we can say that Kyrgyz carpet weaving is endemic. The main focus in this article was made on semantics of carpet weaving traditional custom in the Kyrgyz culture.
\end{abstract}

\section{Keywords}

Carpet, Semantics, Culture, Carpet Weaving, Tradition, Related Customs

\section{Introduction}

The research object in this work is the carpet weaving process of Southern Kyrgyz people. Research subject is carpet weaving sources, preparations, and traditions in the carpet weaving process. The research aim and purpose of this work 
is a comprehensive ethnographic study and analysis of morphological features in the Kyrgyz carpet weaving process as a part of a life support system of ethnos.

Carpet weaving tradition exhibits economic, social, imaginary, psychological, artistic, creative extents in folklore (Öter, 2009). Recent research results showed that native and local wools at national level are more widely used in carpet manufacturing, as an additive for clothing and other items (Bacci et al., 2013). Different color dyes are utilized in the carpet weaving procedure (Ammayappan \& Shakyawar, 2016). Following the previous studies, the products with good emotional designs can attract customers (Du et al., 2018). Traditional crafts including carpet weaving considered as integral part in cultural heritage of any nation reflecting the culture and tradition of a particular region (Yang et al., 2018). Even though carpets cause risk effects on health by holding dust and other air pollutants, carpet floors in public buildings are used to reduce noise, especially in open plan offices and schools, and for aesthetic reasons (Becher et al., 2018). That is why preference should be given to the manufacturing of carpets with dust repelling properties.

In this article, the main focus was made on semantics of carpet weaving traditional custom in the Kyrgyz culture. Following the stated purpose, the focus made on the following tasks:

- Revealing the semantic meaning of carpets and carpet products in the Kyrgyz customs and traditions;

- Revealing the semantics of customs and traditions associated with the process of carpet weaving.

The chronological framework of the study covers the second half of the 14th and beginning of the 20th centuries. The geographical framework is the southern region of Kyrgyzstan located in the Osh and Batken regions.

Research reason is to explore material culture, traditions including carpet weaving tendencies, ethno genetic and historical aspects of Kyrgyzs. The roles of carpets in wedding, in circumcision and other occasions were explained.

\section{Research Design and Methods}

Collected field material allows following those changes, which are subject to this or that rite, which became the possession of history, some elements of traditional weaving are still preserved until today. Besides, the wide attraction of field materials gives an opportunity to trace the ethnocultural relations of the Kyrgyz with other peoples. Collection of materials in this work performed in three stages:

1) Validation of selected material

2) Population survey (free conversation)

3) Processing of the collected materials

Research design was specified according to methodological basis of this work; the principle of historicism and comparative analysis in the diachrony and synchrony of the problem under consideration based on the information collected during interview from informants: 
1) Alimbekova Ajaray, carpet weaver, 58 years old from Aikul village, Kesek tribe

2) Azimova Asylkan, carpet weaver, Aikul village, Kesek tribe

3) Azimova Maria, craftwoman, 60 years old, Aikol village, Kesek tribe

4) Karazakova Altynai, 59 years old, craftwoman in Korgon village, Kesek tribe

5) Aynaz Karazakova is 65 years old, from Korgon village, Kesek tribe

6) Egemberdieva Urkuya, 40 years old, from the town Sulukta, Margun tribe

7) Karazakova Rabiya, 81 years old, craftwoman, Korgon village, Kesek tribe

In the study of the problem, stationary field research methods, interview and comparative analysis were used; traditional carpet weaving, pile weaving is a unique phenomenon of Kyrgyz artistic culture, one of the most widespread types of Kyrgyz folk applied art, which requires systemic research, a significant expansion of the boundaries of comparative analysis, and going beyond the framework of national perception, which provide new facets of ethnos creative expression. As a form of decorative and applied art, carpet weaving has ancient traditions.

\section{Carpet Weaving Process}

In the middle of the weaving process, there is a carpet weaving ceremony performed. Those who do not have carpets are mainly relatives and neighbors. As far as we could see, she was cooking hot meals without "carpeting". The custom of "no rugs" was, in a sense, a sign of encouragement and support for the weaver. Relatives who mourned the carpet used to cook a variety of delicious dishes or send a "plate" from their daughters-in-law. The concept of "escorting a plate" included the addition of delicacies to a large plate, such as rice and flour dishes, traditional boorsok, a basket of bread, and sweets. This is the culmination of rural socialization, mutual support, and strong communication.

Once the carpet is woven, the custom of "carpet tamping" performed, in which last threads of the carpet being cutted from the weaving equipment (a structure built specifically for weaving carpets), after which ready carpet is shaked and carried by sons and daughters in that family. The carpet can be heavy that one or two people are not able to carry it. When carpet is shaking, a lot of dust and wool thread remnants will come out, because in about a month the carpet can absorb the dust. After shaking once again, the carpet will be taken into the backyard and put inside room. If the rug was woven into a girl's dowry, it was kept respectfully until the bridegroom was married. Walnut leaves and sagebrush (ermen) were used to prevent the Witness from falling. The mother used to weave carpets for her sons with good wishes. If the son was married, he delivered the child home immediately. If you are single, you are wrapped up on purpose. The rug is one of the most valuable and expensive items. Relatives and acquaintances did not give up until the carpet is woven. The carpet-weaving house was a separate shed, and if the carpet-weavers had not yet married, the number of visitors to the house would have increased, as they had been tested as the potential bride-to-be. Following the requirements of that time, talented girls 
were very valuable and popular. An example of this is the popular folklore song:

The carpet was laid on the chair

A son like a prince began

The carpet was laid on the tuurduks connection

The bride and daughter were followed

This lyrics dedicated to a woman with great skill and prestige. On the contrary, to the timid wives it was told:

Not hammered the black pole in the ground

Did not put a rug on the place of honor (Antipina, 1962)

After weaving the carpet, the landlord made clothes for the craftsmen (in the Sarpai-Southern dialect) and paid them in cash. Carpet weavers were masters of carpet weaving. According to the experience of carpet weavers, to the carpet weaving was also invited the neighboring villages. Aftet completion of carpet weaving, tea and food was given to neighbors and relatives for celebration (Radlov, 1989).

Carpet weaving was mastered by craftwomen from each village in Chon-Alai, Batken, Leilek, and Nookat regions, example of carpet weaving process is shown in Figure 1.

In Kyrgyzstan, woolen carpets (Figure 2 and Figure 3 ) are used as the most necessary and important items in weddings, bridesmaids' ceremonies, celebrations, circumcisions, and funerals.

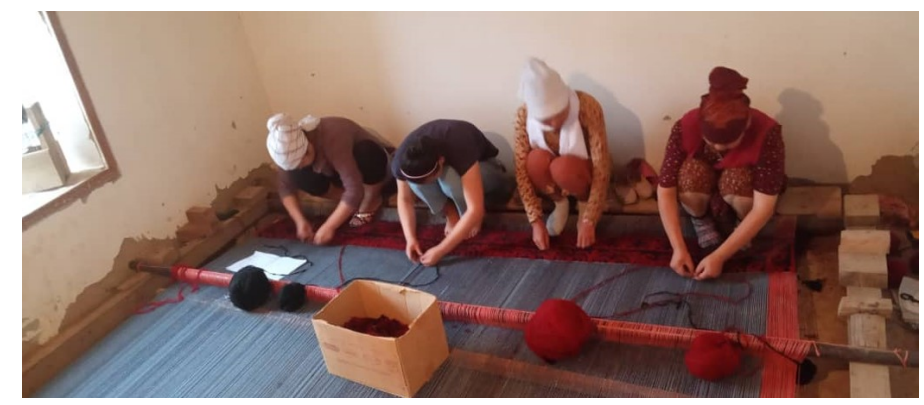

Figure 1. Craftwomen are weaving carpet.

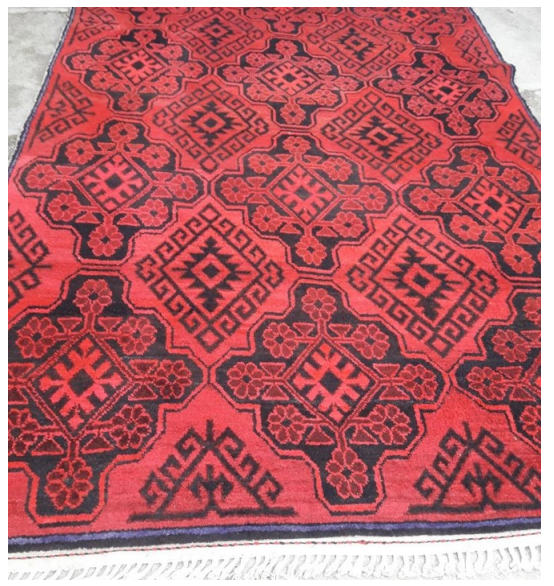

Figure 2. Hand made wool carpet with ornaments. 


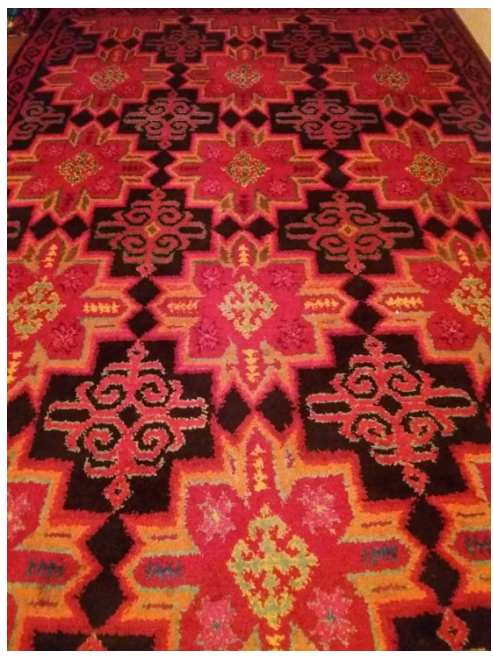

Figure 3. Patterned hand made wool carpet.

Let's look at the semantics and procedures associated with the carpet-making process. Preparing to weave a rug means preparing the rug for a specific purpose. For example, the daughter of a family has grown up or reached puberty. There is a saying among the Kyrgyz people: "If a girl makes a dowry at the age of six, let her make it at the age of seven" (Simakov, 1984). Therefore, in some Kyrgyz tribes it was common for a family to start making dowry and early carpet weaving when a girl was born.

Marriage proposers began to arrive for her adult daughter, so it was necessary to make carpets and rugs, which were one of the most important items for the escort. Therefore, making a rug means being ready to marry a girl. Noticing this, neighbors and relatives noticed that the girl was getting ready for marriage and sometimes suggested that the bridegroom, whom she was looking for, go to the girl's parents to get engaged. The Kyrgyz people proverb says: "If a neighbor is good, a blind girl will find a husband" (Simakov, 1984).

It was believed that a cow with a good carpet would provide sustenance, prosperity, satiety, and abundance. The durability of carpets and rugs, and the fact that their warmth benefited the health of family members, had a higher practical value than the above-mentioned symbolic values (Antipina, 1962). Of course, firstly, it is necessary to consider the utilitarian, practical, and aesthetic aspects of carpets and rugs.

\section{Role of Carpet in Wedding}

At large weddings, carpets were laid not only inside the yurts but also in contact with other yurts outside. This activity was made for the respect of most distinguished guests only when they were available in owners hand (Antipina, 1962). At large weddings, the carpet was not only the decoration of house, but also the status of the owner of the house, where the wedding took place. Also, it can be determined that, the ornaments on carpets and rugs have semantically protective and sacred meaning. At weddings, especially during the bridesmaids' process, 
the girl's mother made a dowry according to her needs, the most important and prestigious of which was a woven woolen rug. K. According to Antipina, marriage settlement was traditionally given to "nine" families (Antipina, 1962). On the right side of the yurt, behind a curtain drawn to the young couples, brides sisters-in-law made carpeting and bedding ceremony. In the process, they tried to put all the bedding in the basket provided by the girl's mother as much as possible on the wedding night of the two young people. Initially, the carpet was woven by the girl's mother herself, or if she could not weave it, the carpet weavers ordered it.

The semantics of this ritual is also very fundamental. While the girl's mother was weaving the carpet, her mother's energy was meant to help her find happiness in the house she was visiting and to make the boy happy. Then they spread wheat and other grain on the carpet without laying any other bedding (Grodekov, 1889). Wheat is the wealth that forms the basis of subsistence farming. Wheat flour is used to make traditional besh barmak, boorsok, and honey boorsok traditional Kyrgyz foods. The main purpose of this ritual was to bring prosperity to the bride house and wish the child to be prosperous and live a sweet life (Rozvadovsky, 1916).

When the girl was escorted, her mother-in-law placed a small carpet on the doorstep, which is called "payandos" in the alcoholic tribes. Once all the gods had entered, one of the girl's closest aunts had the right to take the certain (payandos). Of course, it should be noted that not everyone was able to make a rug, but there were cases when it was replaced by a cloth and a scarf. This depended on the social status of the family (Umetalieva, 1966).

In fact, the standard of living of a homeowner can be determined by the condition of the load inside the house, where the volume and height of the load increased with the accumulation of excess carpets. Carpets were not used as a single household item. According to K.I. Antipina, during the resettlement, the Kyrgyz covered the camel's load with a carpet (Antipina, 1962). Besides, the small carpets woven for these special bots, which covered the camel's calf as a decorative and even protective rug, were called tailak carpets. Thus, the veneration of the camel confirms the Kyrgyzs belief in camel as totem.

\section{Role of Carpet in Circumcision}

One of the initiation processes in the Kyrgyz is the process of circumcision, which may take place in adolescence or younger, with the cleansing of the hands of the son, the performance of the duties of Islam, and the presence of an adult. People gathered animals were slaughtered, and blessings were received from the people for the child's future. There were times when the circumcision ceremony, which was accompanied by entertainment, was celebrated for weeks (Moshkova, 1970). Carpets also play an important role in circumcision. The boy's grandmother from the mothers side made carpets and pillows for his grandson. After the circumcision, the boy's bed was prepared. First, they put a rug under the bed, 
and then they put the mattress to bed so that the child could get better. The boy stays there until he gets up and starts to play, and he is placed in a large cow for those who come to congratulate him on the cleansing of his hands. Relatives, neighbors, and friends come to congratulate the child. This was one of the reasons for the child's enthusiasm, which allowed the child to recover faster and get up without the stress of circumcision. The fact that the carpet, which was considered the most expensive item, was brought to the circumcision ceremony of the son and grandson, equivalent to the foal (tai), wishing that the child's future will be rich and prosperous.

In Kyrgyzs people, support of the young man by his foal (tai) was very significant. His uncles, presented a foal and performed the inheritance ceremony. A male foal was adorned with the most beautiful equipment, and foal was covered by the carpet woven by grandmother and ridden by the circumcised nephew.

Horse equipment was also provided with carpet ornaments. In Kyrgyz people, the horse is highly valued and is considered as the main object in the inheritance ceremony. This tradition is still widespread among the Kyrgyz people until today. According to this tradition, the nephew was connected with the foal. It can be considered as a remnant of the ancient avuncular family form.

The Kyrgyz had great respect to horses. The Kyrgyz boy began to learn to ride a horse at an early age. If a teenager is 3 - 4 years old, then according to the tradition, the saddle was arranged for young children. According to medieval nomadic Kyrgyz tradition, if the owner of a horse dies, the saddle was turned upside down and the horse's tail was cut off, and no one else has ever ridden that horse (Radlov, 1989).

\section{Carpets in Funeral}

Carpets also played an important role during funeral related Kyrgyz traditions. The deceased was laid under carpet or rug. He was then escorted by wrapping in Arabian carpet or felt. It was explained that the more expensive the carpet, the greater his reputation. In addition, expensive carpets were woven during the funeral procession, which was taken to the mosque by the mullahs, and sometimes to the mullahs at the funeral (Moshkova, 1970). This, too, can be seen as the ultimate reverence for the deceased. Also, the fortieth anniversary of the deceased was accompanied by various equestrian games. For example, male cattle (tai) racing, kunan racing, and horse racing (Simakov, 1984). The first nine horses received various gifts. One of the most valuable gifts was these carpets. In Kyrgyz families, carpets are also considered a valuable asset, and if a wife dies without a child, it is passed on to the woman's father (offspring) along with other dowries (Grodekov, 1889). When his wife wanted to divorce him voluntarily, he was left with no property, and he had to leave his dowry in his father-in-law's house and wait out of gratitude.

\section{Conclusion}

In conclusion, one of the main categories of Kyrgyz traditional values is woven 
carpets and rugs. Recently, carpets and rugs have not lost their utilitarian value. In some traditions of modern Kyrgyz life, carpets and rugs are considered as the main attributes. Therefore, we can say that the Kyrgyz carpet weaving process is endemic. Though there are many traditional crafts in different nations, carpet weaving is an endemic craft tradition belonging to Kyrgyz people, which is specifically characterizing their customs.

\section{Conflicts of Interest}

The authors declare no conflicts of interest regarding the publication of this paper.

\section{References}

Ammayappan, L., \& Shakyawar, D. B. B. (2016). Dyeing of Carpet Woolen Yarn using Natural Dye from Cochineal. Journal of Natural Fibers, 13, 42-53. https://doi.org/10.1080/15440478.2014.984054

Antipina, K. I. (1962). Features of Material Culture and Applied Art of Southern Kyrgyz (288 p). Frunze: I AN Kirg.

Bacci, L., Camilli, F., Di Lonardo, S., Duce, P., Vagnoni, E., \& Mauro, A. (2013). Neglected Wools: Fundamental Steps to Counteract the Loss of Potentially Valuable Materials Derived from Native Sheep Breeds. Conference Papers in Science, 2013, Article ID: 402372. https://doi.org/10.1155/2013/402372

Becher, R., Øvrevik, J., Schwarze, P. E., Nilsen, S., Hongslo, J. K., \& Bakke, J. V. (2018). Do Carpets Impair Indoor Air Quality and Cause Adverse Health Outcomes: A Review. International Journal of Environmental Research and Public Health, 15, 184. https://doi.org/10.3390/ijerph15020184

Du, J., Li, Y., Ma, J., Xiong, Y., \& Li, W. (2018). Retrieval of Semantic-Based Inspirational Sources for Emotional Design. Computational Intelligence and Neuroscience, 2018, Article ID: 4685187. https://doi.org/10.1155/2018/4685187

Grodekov, N. G. (1889). Kyrgyz and Kara-Kyrgyz Syr-Darya region. Tom Is the First. Legal Entity(298 p). Tashkent.

Moshkova, V. G. (1970). The Carpets of Central Asia People at the End of XXth to the Beginning of the XX Century (254 p). Tashkent: Fan.

Öter, Z. (2009). Saving Nomadic Cultural Heritage: Carpets for Tourists Woven by Turkish Women. Conference: Women at Threshold of 21st Century: Change and Empowerment, IMWC-International Multidisciplinary Women's Congress, Vol. IV, Izmir, 13-16 October 2009, 643-659.

Radlov, V. V. (1989). From Siberia: Diary Pages (749 p). Moscow: Nauka.

Rozvadovsky, V. K. (1916). Experience of Research of Pottery and Some Handicrafts in Turkestan Region (51 p). Tashkent.

Simakov, G. N. (1984). Public Functions of Kyrgyz Folk Entertainment at the End of XIX to Early XX Century. Historical and Ethnographic Essays (229 p). Leningrad: Nauka.

Umetalieva, K. T. (1966). Kyrgyz Burgundy Carpet. Frunze: Ilim, 74 p.

Yang, Y., Shafi, M., Song, X., \& Yang, R. (2018). Preservation of Cultural Heritage Embodied in Traditional Crafts in the Developing Countries. A Case Study of Pakistani Handicraft Industry. Sustainability, 10, 1336. https://doi.org/10.3390/su10051336 